\title{
Analysis on the Cross-Border E-Commerce Under COVID-19
}

\author{
Yichen $\mathrm{Li}^{*}$ \\ Beijing Normal University-Hong Kong Baptist University United International College, Jintong Road, Xiangzhou \\ District, Zhuhai City, Guangdong Province, China \\ *Corresponding author. Email: m730002063@mail.uic.edu.cn
}

\begin{abstract}
Based on the characteristics of China's cross-border e-commerce, This article analyzes the impact of COVID-19 on cross-border e-commerce of China from three dimensions: foreign trade situation, international logistics and global supply chain. Taking TMALL GLOBAL as a case to analyze. This article outlines the superiorities of cross-border e-commerce industry of China and the issues that need to be resolved in this outbreak: the foreign trade situation is becoming increasingly severe, international logistics is seriously hindered, and global supply chain is disrupted. Then it put forward the corresponding measures to prevent and control the sudden public events that may occur in the future.
\end{abstract}

Keywords: Sudden public events, Covid-19, International trade, Cross-border e-commerce, Business risks

\section{INTRODUCTION}

Under the deep integration of global economic and trade integration, cross-border e-commerce is growing at a high speed in China. The COVID-19 pandemic swept the world in 2020, and the export of most foreign trade enterprises in China was severely hit. Small and medium-sized foreign trade enterprises went bankrupt one after another, and large enterprises were faced with the situation of urgent transformation. Meanwhile, according to the economic survey conducted in the first quarter of 2020 in China, cross-border e-commerce market in China also encountered challenges. In order to alleviate the negative impact of the epidemic, the Chinese government has vigorously promoted favorable policies, and major e-commerce platforms have actively improved their own construction and laid out effective marketing strategies. According to economic surveys conducted in the second and third quarters of 2020, cross-border e-commerce industry in China experienced inverse growth during this period. This paper will further analyze the impact of COVID-19 on cross-border e-commerce of China.

\section{THE OVERVIEW OF CROSS-BORDER E-COMMERCE IN CHINA}

Over the past five years, cross-border e-commerce imports and exports in China have sustained to grow rapidly, which is faster than China's overall import and export growth. Data show that the total amount of cross-border e-commerce transactions in 2019 reached 10.5 trillion yuan, with a year-on-year growth of $16.66 \%$, and an increase of $5.0 \%$ over 2018 , higher than the overall growth rate of import and export of goods of $13.22 \%$. Moreover, data also show that the penetration rate of cross-border e-commerce in international trade reached $37 \%$ in $2019,3.8 \%$ higher than that in 2018, ranking the highest in the world. The online penetration rate of import and export trade is higher than that of domestic online retail trade at $9.9 \%$. Among them, the penetration rate of export e-commerce is higher than that of import e-commerce. Statistics show that cross-border e-commerce exports made up $47 \%$ of total exports in 2019.

In terms of the overall scale of import and export of cross-border e-commerce, the proportion of export in the import and export structure of China's cross-border e-commerce in 2019 reaches $76.5 \%$, the overall scale is 8 trillion yuan, and the proportion of import is $23.5 \%$. In the structure of cross-border e-commerce transactions, the proportion of import and export structure is stable on the whole, but the proportion of import is constantly expanding. Among the 8 trillion yuan export cross-border e-commerce in 2019, the B2B transaction scale accounts for $80.5 \%$, with a year-on-year growth of $11 \%$, about 6.3 trillion yuan; the $\mathrm{B} 2 \mathrm{C}$ transaction scale 
accounts for $19.5 \%$, about 1.73 trillion yuan, with a year-on-year growth of $24 \%$, and the growth rate is much higher than that of the B2B model.

Cross-border e-commerce is the main goal of national strategy in China, and the Chinese government heartens the development of cross-border e-commerce exports. In recent years, the government has provided a rang of preferential policies and infrastructure support for the export cross-border e-commerce industry, and guided the healthy development of the industry through reasonable supervision. it can be perceived that the development status and trend of China's cross-border e-commerce are good. It is believed that with the increasing inclusiveness of global trade and the further deepening of international exchanges, China's cross-border e-commerce will have more and more influence in the world [1].

\section{THE CURRENT STATUS OF CHINA'S CROSS-BORDER E-COMMERCE IN THE CONTEXT OF COVID-19}

\subsection{Foreign Trade is Facing an Unprecedented Grim Situation}

With the outbreak of COVID-19, cross-border e-commerce is facing an unprecedented situation. The difficulties of falling orders, cancellations and delays ensue. According to data from the General Administration of Customs of China, from January to February 2020, China's total import and export value reached $\$ 591.99$ billion, an increase of $-11.0 \%$ year-on-year. Exports totaled us $\$ 292.45$ billion, a year-on-year growth of $-17.2 \%$. Imports totaled US $\$ 299.54$ billion, up $-4.0 \%$ year-on-year. Also, the COVID-19 broke out in foreign countries in March. According to the data, by 17:00 on March 23, a total of 263,893 cases had been confirmed in regions other than China. China's cross-border e-commerce exporters are mainly located in the United States and Europe. The worst-hit areas in Europe have closed cities and other policies, which hinder logistics and further reduce imports and exports. Due to the proper control of the epidemic in China, the exports and imports in China recovered somewhat in the second quarter after a turbulent first quarter. In the second quarter of 2020, China's foreign trade imports and exports reached 7.67 trillion yuan, down $0.2 \%$ year-on-year and 6.3 percentage points less than that in the first quarter. On a monthly basis, exports have achieved positive growth for three consecutive months since April. In June, imports and exports grew $5.1 \%$ year-on-year, including $4.3 \%$ growth in exports and $6.2 \%$ in imports [2].

\subsection{Obstruction of International Logistics}

International logistics are directly affected by the global spread of COVID-19. Usually, international logistics transportation means mainly include air transportation and sea transportation. The decline in international trade under the epidemic has affected the demand for air and sea transport, and the suspension of flights has become the norm. During the 2020 epidemic, the capacity of the international aviation market has declined compared with normal times, and the abdominal logistics capacity of passenger aircraft has therefore been greatly reduced. This has led to an increase in air transportation time and rising prices. Nearly $80 \%$ of cross-border e-commerce sellers said that international logistics prices are rising daily. According to incomplete statistical analysis, from February 2020 to March 2020, the transportation capacity of all international aviation sales markets has dropped by at least $60 \%$ compared with the normal period. As for shipping, according to China's shipping climate report for the first quarter of 2020 released by Shanghai International Shipping Research Center on March 31, China's shipping climate index dropped to 62.95 points due to the COVID-19 epidemic, entering a relatively depressed range. China's shipping climate index hit a record low. So we can see that cross-border logistics is being held up as air capacity declines [3].

\subsection{Global Supply Chains Are Being Restructured}

Today, China plays a prominent role in global supply chains. As a result of COVID-19, production across China has been suspended and production capacity reduced, hitting global supply chains. After the Chinese Spring Festival, the COVID-19 had an impact on export deliveries. According to China's Export Container Freight Index (CCFI), the export freight index dropped from 964.95 to 936.65 around the Spring Festival in 2020, with a decrease of $-2.93 \%$. According to the data, in the 12 years from 2008 to 2019 , the export freight rate index rose in 9 years after the Chinese Spring Festival, and fell in only 3 years, with the biggest drop being $-1.26 \%$ after the Chinese Spring Festival in 2016. It can be seen that the decline of the export freight rate index after the Chinese Spring Festival in 2020 has obviously exceeded the normal historical range. The impact of the current epidemic has been reflected in the freight rate index, which shows that the epidemic has influenced China's export of intermediate products to other countries, causing disruption in the production process of other countries [4].

\section{CASE STUDY: TMALL GLOBAL}

Since February 2020, TMALL GLOBAL has launched a series of support measures to help overseas businesses realize the possibility of sales expansion in the context of COVId-19. TMALL GLOBAL exempted the platform service fee for overseas merchants, 
provided 500 million yuan of low-interest loans to more than 100 merchants, reduced or exempted the bonded warehouse rent, provided logistics initial subsidy, and accelerated the payment of funds to improve the turnover efficiency of merchants and ensure the stock of goods. On April 16, at the TMALL GLOBAL business conference, Liu Peng, president of TMALL import and export business group, released a set of data: from January to march this year, there were 200,000 new products launched in TMALL GLOBAL, and the opening rate of overseas brands increased by $327 \%$ year on year. In February, TMALL GLOBAL international purchases of imported goods by Chinese consumers rose more than $52 \%$ from a year earlier. It can be seen that the measures taken by TMALL GLOBAL have yielded fruitful results. This year, TMALL GLOBAL also launched the "national hot style" contract program to contract a large amount of African Rwanda coffee and Spanish olive oil to help more overseas industrial belt businesses overcome the difficulties caused by the epidemic and explore opportunities in China's import market.

In terms of logistics, TMALL GLOBAL, together with Green Hand, announced the import logistics assistance plan in 2020: it will reduce logistics costs for overseas businesses by 1 billion yuan within one year, helping them overcome the global epidemic. Through the whole logistics link through intelligence, the next year for the international logistics and speed up $10 \%$. On the basis of lowering the processing fee of bonded orders, reducing or exempting the bonded warehouse rent and extending the free warehouse rent, the "one billion Profit Transfer plan" will also have different degrees of profit transfer in the aspects of import logistics, such as port-to-warehouse, central warehouse, inter-warehouse allocation and reverse logistics.

When the offline channel is blocked, cloud services will be further promoted. During the COVID-19 outbreak, TMALL GLOBAL opened a new cloud portal and cloud channel for overseas brands. For example, on March 4 this year, all Nippon airways, a well-known Japanese airline, signed a cooperation plan with TMALL GLOBAL through video connection. In order to speed up the online sales of overseas brands, TMALL GLOBA has also upgraded the language part of its investment promotion website, providing language convenience for overseas brands to apply for entry. TMALL GLOBAL's global investment team covers more than 20 countries in five continents, continuously develops overseas business ecology and supply chain, and provides vertical customized services for overseas brands.

\section{OPPORTUNITIES FOR THE DEVELOPMENT OF CROSS-BORDER E-COMMERCE IN CHINA IN THE POST-PANDEMIC ERA}

The global epidemic of COVID-19 has a profound impact on the global economic development trend, and traditional trade patterns and cross-border e-commerce have shown a trade-off under the impact of the epidemic.

At the national level, China attaches great importance to cross-border e-commerce, a new trade model. The Chinese government vigorously promotes the strategic development of cross-border e-commerce economy, and the central and local governments have issued a series of favorable policies to help cross-border e-commerce. In April 2020, the Executive meeting of The State Council of China decided to set up 46 new comprehensive pilot zones for cross-border e-commerce, so that China will have 105 pilot zones for cross-border e-commerce. With its unique advantages, cross-border e-commerce has become a new major force in foreign trade. From the perspective of consumer demand, during the epidemic, in order to avoid going out for shopping, consumers have become more dependent on online shopping, and online shopping has gradually become the mainstream way of shopping. In addition, cross-border e-commerce provides more convenient channels for consumers to buy overseas goods. The pandemic has promoted the further development of overseas online shopping, and the market of cross-border e-commerce is expanding.

Globally, the cross-border e-commerce market is highly competitive, as a new business model in the Internet era, cross-border e-commerce provides a new channel for China's economic development. It is the general trend of current economic and social development and a new way out for international market competition.

\section{CONCLUSION}

This paper focuses on the analysis of the foreign trade situation, international logistics, global supply chain these three aspects under the influence of COVID-19 challenges. According to the above analysis, we can know that since the outbreak of COVID-19, the three aspects have fallen into a great crisis: the foreign trade situation has become increasingly severe, the international logistics has been seriously hindered, and the global supply chain has been interrupted. Therefore, we should actively take corresponding countermeasures and do a good job of epidemic prevention. The paper also outline the development opportunities for cross-border e-commerce in China with the help of the Chinese government in the post-pandemic era. 
The global spread of COVID-19 has aggravated the vulnerability of the global economy. In this context, re-examining cross-border e-commerce has important theoretical value and practical significance for the sustainable development of China's new trade model. China's customs should make every effort to coordinate the prevention and control of COVID-19 at its ports, promote steady growth of foreign trade, further optimize the business environment at its ports, help enterprises explore the international market, strive to stabilize China's foreign trade base, promote stability and quality of foreign trade, and make important contributions to building China into a trading power.

\section{ACKNOWLEDGMENT}

First of all, I would like to express my gratitude to my tutor and professor who cultivated and educated me. During the writing process of the paper, he took pains to review and guide the paper patiently for many times and gave me many valuable suggestions. I admire him very much for his careful logical thinking. In addition, I would like to thank all my friends and roommates for their encouragement and support. Without their earnest instruction and kind care, I could not have finished my thesis.

\section{REFERENCES}

[1] China's import and export statistics (2019). From: http://www.customs.gov.cn/

[2] Chen, Y. C., Zhou D. Q.(2020). Analysis and forecast of China's shipping boom (the first quarter of 2020). Water Transportation Management, 42(4):35-37.

[3] Hu, L. (2020), National Business News. From: https://www.sohu.com/a/378258576_115362

[4] Meng, L. H.(2020). Opportunities and challenges facing $\mathrm{C} 2 \mathrm{C}$ cross-border e-commerce in the context of COVID-19. Trade Show Economic, (12) 31-33.

[5] Zhang, M. S.(2020). Opportunities and challenges facing cross-border e-commerce enterprises under the "One Belt And One Road" initiative. Shopping Mall Modernization, 68-77.

[6] Zhan, Q., Zhang, C. F., Dong, F., Lv, X. H., Ma, C. P.(2020). A brief analysis of the impact of the new crown epidemic on the development of small and medium-sized cross-border e-commerce enterprises. Management and Technology of Small and Medium-sized Enterprises (SME), 136-137. 